\title{
Financial Inclusion Case Study: Case of Turkey
}

Osman Habeşoğlu ${ }^{a}$,

${ }^{a}$ Near East University, North Cyprus, osman.habes@hotmail.com, https://orcid.org/0000-0003-2485-3772
ARTICLE INFO

Research Article

2021, Vol. 3(1), 40-50

e-ISSN 2667-5927

Article History:

Received: 21.07 .2020

Revised: 06.08.2020

Accepted: 01.11.2020

Available Online: 25.01.2021

JEL Code: G1, G10, G12

Keywords: financial inclusion, development, Turkey
Financial Inclusion Case Study: Case of Turkey

Abstract

Financial inclusion studies became a popular topic nowadays since; the new era development goals are mainly focus on the development of the under developed countries. Particularly, accessing to any form finance is called financial inclusion. Hence this study aims to examine to financial inclusion for women in Turkey. The main conclusion of the paper is that the people especially women who are in the lowest income level are more likely to be financially included to the fourth and third quartile income level. Furthermore, educated people tend to be financially included compere to the others. Lastly, age group of 25-50 are more likely to be financially included.

To cite this document: Habeşoğlu, O. (2021). Financial Inclusion Case Study: Case of Turkey, BILTURK, The Journal of Economics and Related Studies, 3(1), 40-50. doi: 10.47103/bilturk.772689

\section{Introduction}

Financial inclusion has been one of the most important determinant of development in developing countries. Simply, people who have access to financial services (deposit accounts, loans, insurance etc.) are considered as financially included and others who do not have access to these services are considered as financially excluded. There are $2.5 \mathrm{~B}$ people around the world who are financially excluded and estimated number of people who have bank account in developed countries is more than twice of the people who have bank account in developing countries (Hanning and Jansen,2010, World Bank). Demirgunc - Kunt and Klapper (2012) also stated that, portion of the people (older than 15 years) who are financially included is less than $25 \%$ in Africa. Remaining $75 \%$ of people are using informal institutions to borrow or save. 


\subsection{Relevance and Other Studies}

Being financially included is important in aggregate level as a community. Financial inclusion determinants have been one of the most researched topic in economics. Indeed, after the success of Professor Muhammad Yunus, founder of Grameen Bank, microfinance became a popular topic among researchers. Generally, financial institutions quality's is related with financial inclusion in both developed and developing countries, in particular, the importance of micro-finance institutions is much more important in developing countries. Being financially excluded also implies that people have numerous disadvantages, such as, facing with high cost of borrowing or saving (Gross et al, 2012; Barr, 2004).

A good financial system (FS) (markets or/and banks) is a key element of financial inclusion (Levine, 2004; Honohan,2008). Levine (2004) identified and summarized five key functions that a financial system provides in facilitating growth hence poverty reduction. A good FS provides 1) Mobilizing and pooling savings, 2) production information ex ante about possible investments and allocating capital, 3) Monitoring investments and exerting corporate governance, 4) Facilitating the trading, diversification, and management of risks and 5) Facilitating the exchange of goods and services (Zhuang et al, 2009).

Indeed, Turkey is one of the countries which saw the importance of financial inclusion in growth process. Thus, policy makers and politics have focused on increasing financial inclusion within the country by considering all population. Beside achieving growth, poverty reduction is another target in Turkey. Improving financial inclusion among a country level is not an easy task. There are lots of obstacles for both demand and supply side. One possible solution to these obstacles, a study by Nobel Laureate Muhammad Yunus has proved that an institution can lend to poor people without any collateral. With this success in mind, some people had a head-start to improve financial inclusion in early 1980s in Turkey. The first institution was "Foundation for The Support of Women's Work" and also known as "FSWW". FSWW was founded as a non-profit civil society organization in 1986 to support improving the quality of life and economic situation of low-income women and strengthen their leadership in local development. The foundation also subsidized by government. In July 2003, "Turkey Grameen Microfinance Program (TGMP)" was founded by the Turkish Foundation for Waste Reduction as a BOT(Build-Operate-Transfer) in partnership with Grameen Trust. So far, TGMP has disbursed over 92.4 million $\$$ (164.5 Millions TL) to over 93,000 borrowers. TGMP currently has 90 branches throughout Turkey, with a high concentration in the higher-poverty regions of the south and east. Both FSWW and TGMP have a common target borrowers' which are women. Furthermore, there are some government banks which support micro-credit for small enterprises and poor 
people as well. The common and most popular banks are; Ziraat Bank for farmers and HalkBank for enterprises.

\subsection{Research Objective and Questions}

The main purpose of this study is to examine the financial inclusion in Turkey and specifically, aims to answer following research questions:

1- Does the gender an obstacle for financial inclusion?

2- If yes, does income level of women affect her financial inclusion?

\subsection{The Study Area- Turkey}

Turkey is a transcontinental country in Eurasia, mainly in Anatolia in Wester Asia with smaller portion on the Southeast Europe. Turkey is bordered by eight countries: Greece to the west; Bulgaria to the northwest; Georgia to the northeast; Armenia, the Azerbaijani exclave of Nakhichevan and Iran to the east; and Iraq and Syria to the south. Turkey has the world's 18th largest nominal GDP and the country is among the founding members of the OECD and The G-20. By 2015, Turkey has 717.88 Billion GDP (current US\$) and 78,665,835 populations in total.

\section{Method}

This part of the study describes the methodology and the sources of secondary data to be used. It also presents the econometric model and explanation of estimation method of the study.

\subsection{Data Type and Source}

Global Financial Inclusion Database (FINDEX) is a data set to be used in this study. The indicators in the 2014 FINDEX database are drawn from survey data covering almost 150,00 people in more than 140 economies, representing more than 97 percent of the world's population. The survey was carried out over the 2014 calendar year by Gallup, Inc. as part of its Gallup World Poll, which since 2005 has continually conducted surveys of approxi-mately 1,000 people in each of more than 160 economies and in over 140 languages, using randomly selected, nationally representative samples. The target population is the entire civilian, noninstitutionalized population age 15 and above (The World Bank, 2016).

\subsection{Descriptive Statistics}

To understand and analyze the nature of the date this section illustrates some descriptive statics about independent variable.

The data set includes 1002 individuals across Turkey. People who are between the age of $15-25$ are 272 which makes roughly $27 \%$. The pie chart below gives the percentage of the individuals who belong to given age group. Similarly, there are $163,235,179$ and 153 people in the age interval 26-35, 36-45, 46-55 and more than 55 respectively. The data set is nearly normally distributed, it contains 502 females 
and 500 males. Thirdly, it has been assumed that, people who has education level more than secondary school considered to be educated and others who do not have education level more than secondary level considered to be uneducated. Therefore, under this assumption, percentage of people who attended the secondary school or more, is $80 \%$ and others $20 \%$. From given results, it is clear that people in Turkey usually complete, at least secondary school. Finally, to compare income level of the respondents, the data set gives that; $16.07 \%, 18.66 \%, 17.76 \%$, $19.06 \%$, and $28.45 \%$ of the respondents belongs to Income Quartile 1,2,3,4 and 5 respectively. The bar chart below, also represents the number of people in each income quartile.

Figure 1: Descriptive Statics
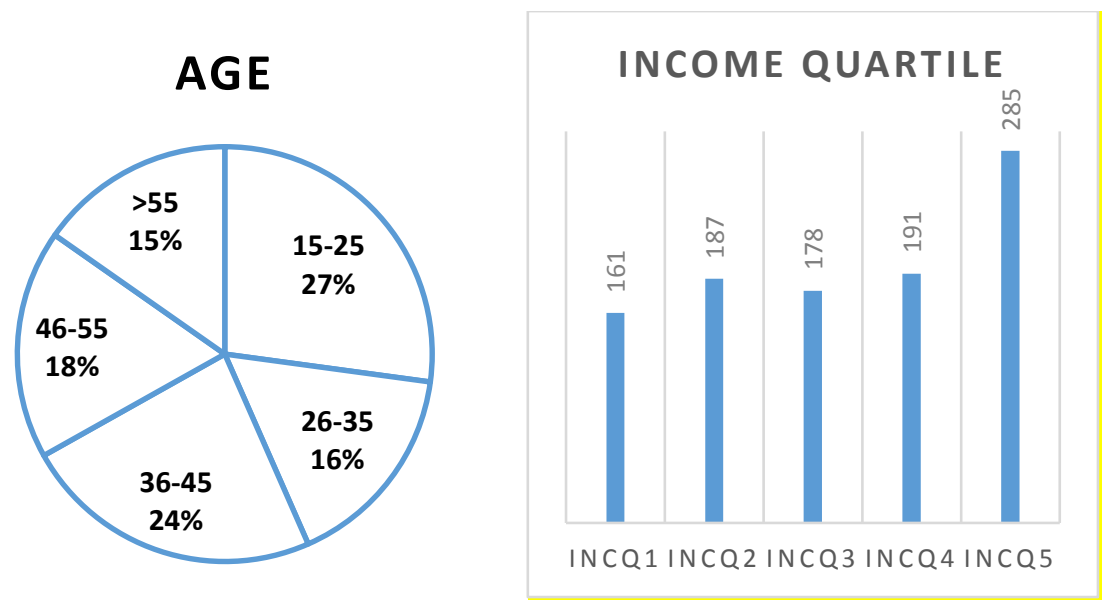

Source: Researcher's own construct, 2017.

\subsection{Econometric Model and Explanation Of Estimation Method}

In some cases, dependent and independent variables have quantitative meaning, such as; hourly wage rate, years of education etc. In each case, the magnitude of the variable gives useful information. However, on the other hand, sometimes qualitative variables can be included in the model. For example, the gender or race of an individual or an individual has bank account or has not.

Qualitative factors often come in the form of binary information: as explained above, gender of an individual can be either male or female. The relevant information can be captured by defining a binary variable or a zero-one variable (variable can only take values 1 and 0 ). In econometrics, binary variables are commonly called dummy variable (Wooldridge, 2013). 
In this study, Logit Model is going to be used as an estimation method. These methods also known as binary response models and are modified versions of linear probability model (LPM). The reason Logit model to be used is because LPM has some drawbacks such as, fitted probabilities can be less than zero or greater than one and the partial effect of any explanatory variable is constant (Wooldrige,2013). By using Logit estimation method, the possibility of these problems will be minimized.

The possible model for this specific research will be;

$P(Y=1 \mid x)=G($ Age, Age2, Female, Literacy, IncQ1, IncQ2, IncQ3, IncQ4)

Where;

Y Represent: Financial inclusion level, or an individual has bank account or not.

Inc $Q_{1}$ represent: Within - economy household income quintile, Poorest $20 \%$

Inc $Q_{2}$ represent: Within - economy household income quintile, Second $20 \%$

Inc $Q_{3}$ represent: Within - economy household income quintile, Third $20 \%$

$\mathrm{Inc}_{4}$ represent: Within - economy household income quintile, Forth $20 \%$

Table 1 represents model of measurement of each variable, and expectations.

Table 1: Measurement of Each Variable and Expectations

\begin{tabular}{lll}
\hline \hline Dependent Variable & Measurement & Expectation \\
\hline \hline $\mathrm{P}(\mathrm{Y}=1 \mid \mathrm{x})$ & 1 or 0 & ------- \\
Independent Variable & & \\
Age & Years & Positive \\
Age2 & Years & Negative \\
Female & 1 or 0 & Negative \\
Literacy & 1 or 0 & Positive \\
IncQ1 & 1 or 0 & Negative \\
IncQ2 & 1 or 0 & Negative \\
IncQ3 & 1 or 0 & Negative \\
IncQ4 & 1 or 0 & Negative \\
\hline \hline
\end{tabular}

Source: Researcher's own construct, 2017.

In more specific way, Model 1 can be written as:

$P(Y=1 \mid x)=\beta_{0}+\beta_{1}$ Age $+\beta_{2} A_{\text {ge }}{ }^{2}+\beta_{3}$ Female $+\beta_{4}$ Literacy $+\beta_{5}$ Inc $_{1}+\beta_{6}$ Inc $Q_{2}+\beta_{7}$ Inc $Q_{3}$ $+\beta_{7} \operatorname{lncQ}_{4}+\mu$

In the nature of binary response models, the primary goal is to explain the effect of the $x_{j}$ on the response probability $P(y=1 \mid x)$. (Wooldridge, 2013). Equation 2, aims to capture, at least, the part of the independent variables that affects financial inclusion. As it is not possible to include all variables in the model, the assumption will be, the error term $(\mu)$ captures other independent variables that might affect 
the financial inclusion. As shown in Table 1, most of the variables that included to the model are binary independent variables which can only take values of 1 or 0 . Income quartile 5 , also known as richest $20 \%$ of the population has not included the model because, it considered as a base category. Therefore, each coefficient for income quartiles will give a comparison between richest $20 \%$ and given income quartile. Being female also included to model as binary independent variable, and aims to capture difference between males and female. Similarly, male has not included to model and considered as a base category for gender. Age is the only continuous independent variable in this model, however, in order to capture any diminishing effect age_sq has to be included. It is likely to observe that age has a diminishing effect on any model. Lastly, education is also considered as a dummy variable in the model. It is also possible to change education to categorical variable if the results will not significant.

\section{Results}

This section aims to provide an overview of the output which obtained from Gretl. The results that going to be discussed in this section only reflect a descriptive statistics and outcome. The detailed version of the results will be discussed in the "Discussion" section.

In overall, it has been found that, all independent variables are statistically significant at 5\%. The model also gives Likelihood Ratio (LR) of 161,972 which is statistically significant at $5 \%$. Significance of LR means that independent variables which included to the logit regression are jointly affect the probability of financial inclusion. Another important finding is that, the regression gives $0.1227 \mathrm{McF}$ adden $\mathrm{R}$-squared which means that, the independent variables which included to model are able to explain $12.27 \%$ of variations in probability of Financial Inclusion.

Therefore, equation (2) becomes as follows;

\section{$P(Y=1 \mid x)=-1.558+0.1163$ Age -0.0011 Age $^{2}-1.1931$ Female + 0.976 Literacy -0.7724 IncQ $_{1}-0.8837$ IncQ $_{2}-8439$ IncQ $_{3}-0.704$ IncQ $_{4}$

As mentioned before, age, age2, gender, literacy and income quintiles are all statistically significant at $5 \%$. As expected, age has positive effect on probability of financial inclusion and age 2 has negative effect on probability of $\mathrm{Fl}$. This relationship can be described by quadratic functions definition. As individuals grow, they reach the peak point of the FI probability, at this point an individual has the highest probability that being financially included. However, once an individual become older than that age, the probability of being financially included start to diminish hence reduce. To capture any diminishing effects, age2 has to be included 
in the model. The probability of an educated male who has high income (richest $20 \%$ ) is about $88.14 \%$ at the age of 32 .

Secondly, being female also has a negative effect on probability of FI and this result also support the initial expectation about gender issue. The regression results show that, females are $26.40 \%$ less likely to be financially included compare to males when all other variables are fixed.

Thirdly, education is another important determinant of FI in Turkey. From given regression results, educated respondents are $23.26 \%$ more likely to be financially included compare to non-educated people, when all other variables are fixed. This result also supports the initial expectations. In terms of education, it has been assumed that people who have education level more than secondary education, considered to be educated and take value of 1 , others considered to be uneducated and take value of 0 .

Last but not least, it has also been found that level of income also negatively correlated with the probability of FI. Respondents who are at the lowest income quartile are $18.43 \%$ less likely to be financially included compare to highest income quartile respondents. Similarly, people in second, third and fourth income quartile are $19.86 \%, 20.13 \%$ and $16.69 \%$ less likely to be financially included compare to highest income quartile when all other variables fixed.

Lastly, to understand how high and low the actual population value of the independent parameter can be, confidence interval gives useful information. Table 2 illustrates the confidence interval for each coefficient. It is important to note that, confidence intervals do not reflect the marginal effects but give useful information about the direction of the marginal effect.

Table 2: Logit Regression

\begin{tabular}{|c|c|c|c|c|c|}
\hline \multirow[b]{2}{*}{ cons } & \multirow{2}{*}{$\begin{array}{l}\text { Coefficient } \\
-1,5577\end{array}$} & \multirow{2}{*}{$\begin{array}{l}\text { P-Value } \\
0,0033\end{array}$} & \multirow[t]{2}{*}{ Slope } & \multicolumn{2}{|c|}{ 95\% Conf. İnterval } \\
\hline & & & & $-2,67709$ & $-0,4445$ \\
\hline Female & $-1,193$ & 0 & $-0,264$ & $-1,479$ & $-0,9071$ \\
\hline Age & 0,1163 & 0,0001 & 0,0263 & 0,0688 & $-0,1637$ \\
\hline Age_sq & $-0,0011$ & 0 & $-0,0003$ & $-0,0017$ & $-0,0006$ \\
\hline Edu & 0,976 & 0 & 0,2326 & 0,6044 & 1,3476 \\
\hline IncQ1 & $-0,7724$ & 0,0009 & $-0,1843$ & $-1,2277$ & $-0,3171$ \\
\hline IncQ2 & $-0,8337$ & 0,0002 & $-0,1986$ & $-1,2865$ & $-0,3809$ \\
\hline IncQ3 & $-0,844$ & 0,0002 & $-0,2013$ & $-1,2847$ & $-0,4033$ \\
\hline IncQ4 & $-0,704$ & 0,00012 & $-0,1669$ & $-1,1271$ & $-0,2808$ \\
\hline \multicolumn{2}{|c|}{ McFadden R-squared } & \multicolumn{4}{|c|}{0,1227} \\
\hline \multicolumn{2}{|c|}{ LR test } & \multicolumn{4}{|c|}{161,972} \\
\hline \multicolumn{2}{|c|}{ Correctly preducted } & \multicolumn{4}{|c|}{$674(67,3 \%)$} \\
\hline
\end{tabular}

Source: Researcher's own construct, 2017. 


\section{Discussion}

As a main objective of this study, the aim is to identify whether women face with financial exclusion in Turkey or not. Furthermore, study aims to answer whether income level of women related to financial inclusion. In other words, the study seeks to answer how likely is a low income woman tends to be financially included.

The estimated Logit model gives an idea about these issues. It has been found that women tend to be less likely to have a bank account hence financially included in Turkey compare to men. From given results, as discussed in former section, women are $26.40 \%$ less likely to have a bank account. This finding is consistent with study done by Olga Tomilova, 2015. Tomilova 2015, reported that, number of women among account holders is about $44 \%$ while number of men who have bank account is $69 \%$. This finding clearly answers the first hypotheses question.

In terms of income level, it has been found that income level has negative effect on financial inclusion for both females and males. Second and third poorest income levels have the biggest negative effect on financial inclusion. Poorest income group tend to be less likely to be financially excluded compare to second and third income quartile groups. This finding might sounds odd but in practice it is true and consistent with Tomilova, 2015. In 2014, Turkey launched the development of the "Financial Inclusion Strategy" which aims to improve access to finance for youth and vulnerable groups such as women and migrants (Tomilova, 2015). These people, mainly, form the poorest $20 \%$ and since the "Financial Inclusion Strategy" focuses on these groups, it is possible to say that the regression results are acceptable for income level.

In overall, income level of women is negatively correlated with probability of financial inclusion in Turkey. If a woman belongs to second and third income level, she is $20 \%$ less likely to have an account when all other variables are fixed.

On the other hand, education as a second important element of the estimated model is significant at $5 \%$. Education increases probability of financial inclusion by $23.26 \%$ which is the second highest marginal effect among independent variables. However, as discussed former section, education variable considers people who have education at secondary level or more as educated or vice versa. Therefore, the given coefficient only captures the marginal effect of education in aggregate level rather than in detail so it can be discussed further but since the aim of this study addressed to gender and income level issues, education will not be reassessed in this study.

Secondly, an additional test has been done in order to check, if independent variables are simultaneously significant or not. To carry out this, "Wald test" has been done with Gretl. As a result of the test, null hypothesis rejected and 
independent variables are not simultaneously equal to zero. Therefore, removing an independent variable from the model means that the predicted value of Financial Inclusion will be less accurate.

On one hand, heteroscedasticity could be a serious problem for logit model, since it renders parameter estimates inconsistent. Moreover, because logit model is usually estimated with cross-section data, it is a problem which is likely to be encountered quite often. On the other hand, heteroscedasticity cannot properly be tested but some forms of LM tests can be used test for heteroscedasticity. However, these tests can behave very differently from each other, therefore, heteroscedasticity cannot properly be identified in logit models (Davidson and MacKinnon,1984).

Lastly, there could be some database specific limitations to this study. Indeed, Demiguç - Kunt and Klapper, (2012) have reported that "indicators based on data collected from financial service providers have several important limitations". First, regulated financial institutions supply the data and thus this give fragmented view of financial access. However, Global Findex database formed via individual respondents from segments of the population across 148 economies hence this give a broad overview of the data. Therefore, first limitation does not seem as a problem for this study. Second, aggregation can be misleading because of multiple accounts or dormant account. Multiple accounts are common in worldwide, for example, an individual could have saving accounts at more than one institution, hence, it is possible to overestimate per capita account hence financial inclusion. This option does not seem as a problem for this study since the data reflects individual respondents. In contrast, some people could have joint ownership of an account, which could lead to underestimation of per capita account. Indeed, this could be a possible limitation for this study, for example, if data collected from a couple who has one joint ownership of an account, both female and male are likely to report that, they have an account. But, it is also possible to argue that, she has been forced by her husband to apply a loan account (ie. some institutions give loans to females easier than males) but she does not have an access to finance for herself hence could be classified as financially excluded in practice. But, in the regression this possibility will increase probability of Fl for females. Therefore, it is difficult to measure the net effects of these kind of problems.

To conclude, all independent variables found to be jointly significant in this study, but there are some database specific limitations which discussed above. These limitations cannot be solved by using econometric tools, but more complex models might give more accurate result. Global Findex database is the best available secondary data for this kind of studies. Therefore, it is fair to say that, database specific limitations have been minimized. 


\section{Conclusion and Recommendations}

This paper aims to answer two main questions about financial inclusion in Turkey. In other words, it seeks to find if women are financially excluded or not in Turkey. The Global Findex database (2014) has been used as a secondary data source. Global Findex is the most reliable database among others and it gives data about financial inclusion indicators for 140 countries.

In overall, it has been found that women are $26.40 \%$ less likely to be financially included in Turkey. Indeed, World Bank and Tomilova (2015) have reported that $44 \%$ of women are financially included while $69 \%$ of men are financially included in Turkey. Moreover, income level also plays important role on financial inclusion. Regardless the gender of a person, people who are in the poorest income quartile are $18.43 \%$ less likely to be financially included compare to richest $20 \%$ of the population. However, an interesting finding is that, second and third $20 \%$ income levels are found to be the most financially excluded groups. Both second and third $20 \%$ of the people are nearly $20 \%$ less likely to be financially included compare to richest $20 \%$. At this point, it is possible to make few recommendations for those groups who are less likely to be financially included. The possible recommendations are as follows:

$>$ These people are usually active workers at the younger ages (20-55) therefore more likely to be financially included at those ages. However, when they became older, they do not earn as much as money as before so they became more likely to be financially excluded. At this point, government or other authorities should support these people by making access to finance easy. Government could expand micro finance institutions to wider sections of the population rather than only poorest $20 \%$.

$>$ There should be some saving banks within the country. The main objective of these banks should be help the people to save for their future, so older people can enjoy their retirement.

To conclude, nearly more than the half of the women are financially excluded in Turkey and there is a significant difference between females and males. However, this gap is relatively small compare to other developing countries and probably will decrease in the future. 


\section{References}

Barr, M. (2004). Banking the Poor, Yale Journal of Regulation, 21(1), pp. 121-237.

Davidson, R. and MacKinnon, J.G. (1984). Convenient specification tests for logit and probit models, Journal of Econometrics, 25(3), pp. 241-262.

Demirguc-Kunt, A. and Klapper, L. (2012). Measuring financial inclusion: The global Findex database. The World Bank.

Gross, M. and Hogarth, J. (2012. Use of Financial services by the Unbanked and Underbanked and the Potential for Mobile Financial Services Adoption. Board of Governors of the Federal Reserve System. Federal Reserve Bulletin, 9 (4).

Group, T.W.B. (2016). Global financial inclusion (global Findex) database. Available at: http://data.worldbank.org/data-catalog/financial_inclusion (Accessed: 28 February 2017).

Hannig, A. and Jansen, S. (2010). Financial inclusion and financial stability: Current policy issues, SSRN Electronic Journal.

Honohan, P. (2008). Cross-country variation in household access to financial services, Journal of Banking \& Finance, 32(11), pp. 2493-2500.

Levine, R. (2004). Finance and Growth: Theory and Evidence. NBER Working Paper No. 10766, National Bureau of Economic Research, Cambridge, MA. Available: www.nber.org/papers/ w10766.

Tomilova, O. (2015). Progress and opportunities for financial inclusion in Turkey. Available at: http://www.cgap.org/blog/progress-and-opportunities-financialinclusion-turkey (Accessed: 22 February 2017).

Wooldridge, J.M. (2013). Introductory econometrics: A modern approach. 5th edn. Melbourne: South-Western College Publishing.

Zhuang, J., Gunatilake, H.M., Niimi, Y., Khan, M.E., Jiang, Y., Hasan, R., Khor, N., Martin, A.L., Bracey, P. and Huang, B. (2004). Financial sector development, economic growth, and poverty reduction: A literature review, SSRN Electronic Journal, . 